\title{
Microsatellite Analysis of Microdissected Tumor Cells and 6p High Density Microsatellite Analysis in Head and Neck Squamous Cell Carcinomas with Down-Regulated Human Leukocyte Antigen Class I Expression
}

\author{
Manita Feenstra, Marina Verdaasdonk, Anne Wil van der Zwan, Roel de Weger, \\ Pieter Slootweg, and Marcel Tilanus \\ Department of Pathology, University Medical Center, Utrecht, The Netherlands
}

\begin{abstract}
SUMMARY: Down-regulated human leukocyte antigen (HLA) class I expression is frequently correlated with allelic loss at 6 21.3, which is the location of the HLA coding sequence, in head and neck squamous cell carcinomas (HNSCCs). Previously, we have demonstrated loss of heterozygosity $(\mathrm{LOH})$ at $6 \mathrm{p} 21.3$ for at least one locus in $49 \%$ of the HNSCCs using 5 microsatellite markers spanning the 4 megabase HLA region. In the present study, the detection threshold (25\%) to assign LOH was addressed by laser-assisted microdissection of tumor cells from tumors containing marginal loss. In addition, we describe high density microsatellite analysis of chromosome 6p21.3 in HNSCC with down-regulated HLA class I expression. The purpose of this study was to refine the identification of genetic alterations at 6p21.3 and to pinpoint allelic loss to individual HLA class I genes, using additional markers closely located to the HLA-A, -B, and -C loci and the transporter associated with antigen processing (TAP) genes. $\mathrm{LOH}$ analysis by amplification of microsatellite markers and subsequent fluorescent detection is a rapid and sensitive technique to predict HLA class I loss phenotypes in tumors. LOH can be identified at $25 \%$ relative signal reduction. Analysis of heterogeneous tumor samples and samples containing a small amount of tumor cells is facilitated by laser-assisted microdissection of tumor cells. In addition, we showed that accurate HLA LOH analysis requires application of microsatellite markers in close proximity to HLA class I and TAP genes. (Lab Invest 2000, 80:405-414).
\end{abstract}

$L$ arge scale genomic sequencing of the human leukocyte antigen (HLA) coding region has resulted in the identification of an increased microsatellite marker density in the central part of the HLA region (class II, class III, class I-class III junction) (Fossaic et al, 1997, 1998), the HLA class I region (Tamiya et al, 1998), and the centromeric region (6p21.2-6p21.3) (Tripodis et al, 1998). Approximately one polymorphic marker every 34 to $66 \mathrm{~kb}$ on average can be found in the HLA class I region spanning from HLA-B to HLA-E (Tamiya et al, 1998). HLA microsatellites have been applied in disease susceptibility, population, transplantation, and recombination studies (Fossaic et al, 1998). The HLA gene complex encodes for many genes involved in immune responses.

The HLA class I and class II genes encode highly polymorphic, cell surface glycoproteins that bind antigenic peptides for presentation to CD8 and CD4 bearing cytotoxic $\mathrm{T}$ lymphocytes, respectively (Townsend and Bodmer, 1989). The high degree of polymorphism en-

Received November 22, 1999.

Address reprint requests to: Dr. M. G. J. Tilanus, Department of Pathology, H04.312, University Medical Center, P.O. Box 85500, 3508 GA Utrecht, The Netherlands. Fax: 3130254 4990; E-mail:M.Tilanus@lab.azu.nl ables binding and presentation of a wide range of peptides. Peptides bound by HLA class I molecules are generated from endogenous peptides by a multicatalytic complex, the proteosome, and loaded onto HLA class I molecules by transporters associated with antigen processing (TAP) heterodimers (Maffei et al, 1997). The gene encoding components of the proteosome (low molecular mass protein[LMP] 2 and 7) and for TAP 1 and TAP 2, are located within the class II region (Campbell and Trowsdale, 1993). Recognition of peptides derived from viral proteins or tumor antigens by cytotoxic T cells (CTLs) induces immune responses that ultimately result in lysis of the target cell. Downregulation or absence of particular class I molecules at the cell surface has been shown in many human tumors, thereby providing tumor cells with a mechanism to escape recognition by the immune defense system (Ferrone and Marincola, 1995; Garrido et al, 1995; 1997).

Recently, we reported a correlation of downregulation or loss of HLA class I expression in head and neck squamous cell carcinoma (HNSCC) and loss of heterozygosity $(\mathrm{LOH})$ at 6p21.3 (Feenstra et al, $1999 b)$. HLA class I, beta2-microglobulin $(\beta 2 \mathrm{~m})$, and TAP expression was characterized by immunohistochemical procedures. LOH analyses was performed using five microsatellite markers (STRs) (D6S291, 
D6S273, D6S265, D6S105, and D6S276) spanning the 4 megabase HLA region at $6 \mathrm{p} 21.3$ and two STRs located at the centromere (D6S473) and telomere (D6S277), respectively. In addition, two microsatellite markers flanking the $\beta 2 \mathrm{~m}$ gene on 15q (D15S126 and D15S153) were used to study allelic loss of $\beta 2 \mathrm{~m}$. High frequencies of allelic deletions were found at D6S291 (36\%), and at the HLA class I located D6S265 and D6S105 markers (33\% and 27\%, respectively) in the tumors with down-regulated HLA class I expression. Loss at D6S291 (located in the vicinity of the TAP genes) significantly correlated with down-regulated HLA class I and down-regulated or negative TAP expression ( $p=0.0196$ and $p=0.0464$, respectively). Allelic loss at $15 q$ was found in $29 \%$ of the HNSCC with down-regulated HLA class I expression. Loss of heterozygosity was assigned at a threshold of $25 \%$ signal reduction of one allele in the tumor compared with the normal sample.

The aim of the present study was to assess the detection threshold (25\%) in tumors containing marginal loss. This was performed on microdissected tumor cells, which facilitates interpretation of allelic loss by avoiding amplification of co-isolated DNA derived from stromal and infiltrating cells. Allelic loss to loss of HLA class I and TAP genes was pinpointed by application of an extended panel of STR markers selected for their close proximity to the HLA and TAP genes (Fig. 1). In addition, a $6 q$-located marker was selected to be able to assign loss of an entire chromosome 6.

\section{Results}

\section{LOH Analysis on Microdissected Tumor Cells}

Previously, 55 HNSCC were studied for LOH using seven microsatellite markers located on chromosome 6 and two markers flanking the $\beta 2 \mathrm{~m}$ gene (Feenstra et al, 1999b). Most samples showed residual amplification of the lost allele in the tumor from co-isolated DNA derived from stromal cells. By definition, allelic loss was assigned if $25 \%$ and more of signal reduction of one allele was shown in the tumor sample compared with the normal sample. In four tumors, near-threshold values of signal reduction compared with the normal sample were found. To clarify whether these samples displayed allelic loss, tumor cells from these samples were microdissected to avoid co-isolation of stromal and infiltrating cells. In addition, stromal and epithelial cells of these tumors were separately microdissected and used as a control.

Three of the samples showed a $25 \%$ to $30 \%$ signal reduction with marker D15S126. An example for marker D15S126 is shown in Figure 2. Amplification and gene scan analysis of nonmicrodissected tumor cells resulted in two alleles (Fig. 2b). One allele in the tumor sample showed a reduced intensity compared with the normal sample, which was derived from microdissected epithelium cells (Fig. 2a). Amplification and gene scan analysis of microdissected normal epithelium cells showed two alleles of equal heights

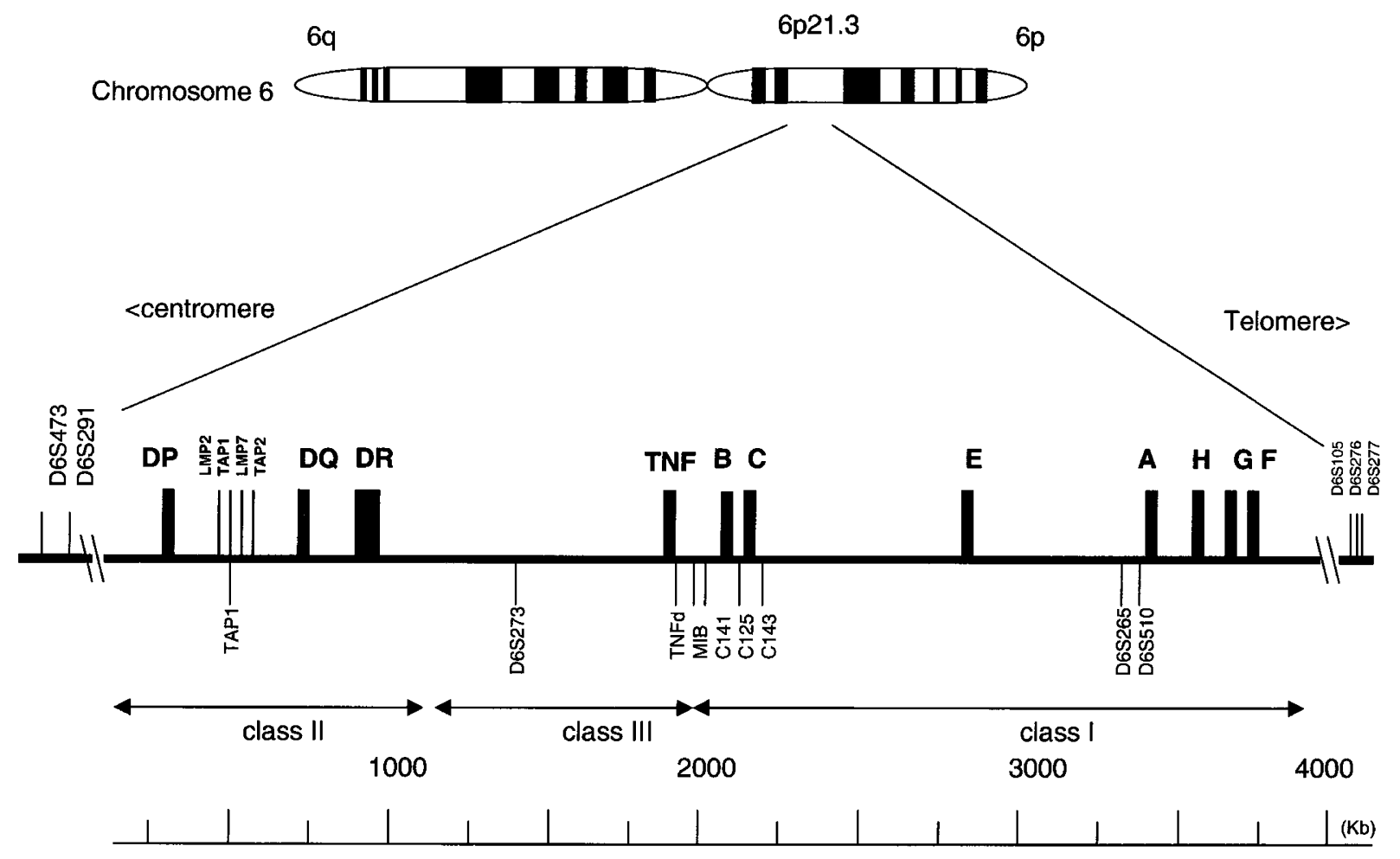

Figure 1.

Schematic presentation of the location of the short tandem repeats (STRs) on chromosome $6 \mathrm{p}$ and their relative position to the HLA-A, -B, -C, TAP1, and TAP2 genes. 


\section{Allelic loss in micro-dissected tumour cells}

D15S126

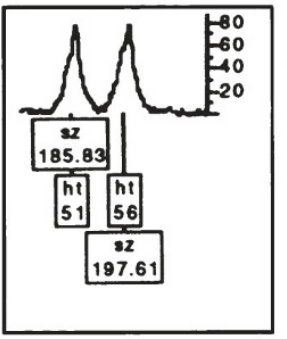

Epithelium
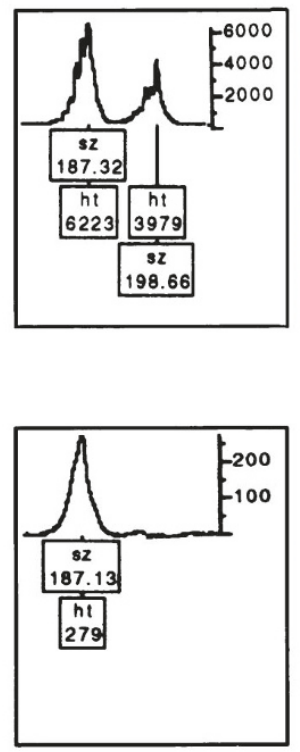

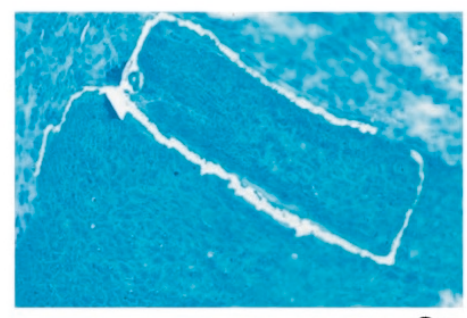

2a

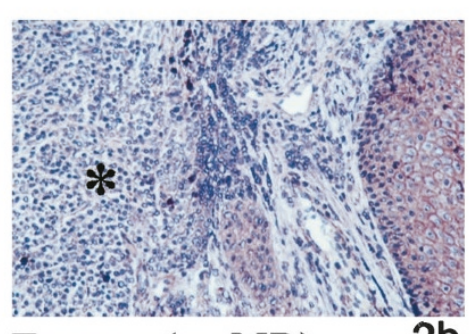

Tumour (no MD)

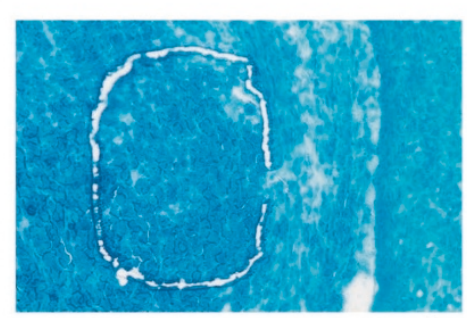

Tumour (MD)

$2 b$

2c
D6S265

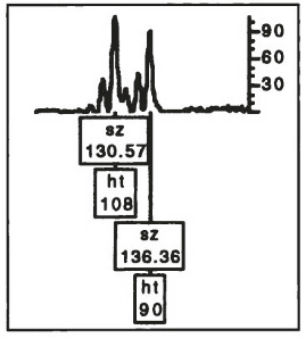

Stroma
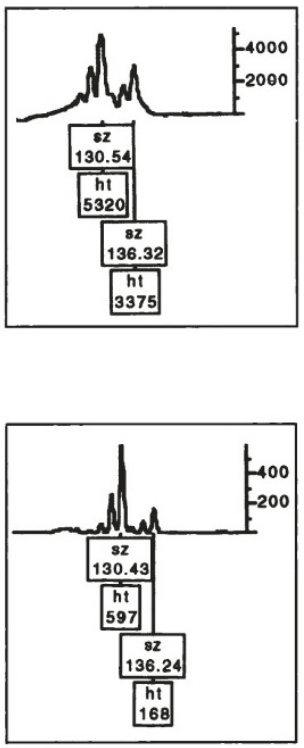

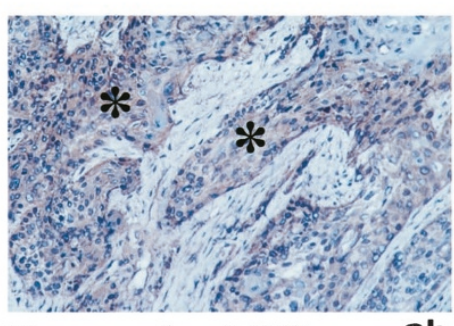

Tumour (no MD)

3b

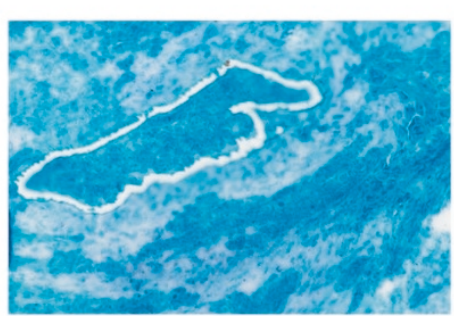

Tumour (MD)

\section{Figure 2.}

Loss of heterozygosity (LOH) analysis using marker D15S126.

\section{Figure 3.}

LOH analysis using marker D6S265. LOH analysis was performed on normal microdissected epithelial or stromal cells, nonmicrodissected tumor cells and microdissected tumor cells. Sections were used for microdissection were stained by toluidin blue (2a and 2c, 3a and 3c). The figures show the areas of tumor (2c and $3 c$ ) or normal cells (2a and $3 \mathrm{a}$ ) that were microdissected. The nonmicrodissected sections were immunostained using anti-â2m monoclonal antibodies (mAbs) (2b) or the monomorphic anti-HLA class I mAb W6/32 (3b). For LOH analysis of the nonmicrodissected tumor, the whole section was used, of which only a part is shown. Sections contained at least $60 \%$ tumor cells (estimated). Tumor cells are indicated with asterisks. Amplification and subsequent gene scan analysis of the samples was performed using marker D15S126 (2a to 2c) or marker D6S265 (3a to 3c).

(Fig. 2a). LOH of this sample was calculated as follows:

$\begin{aligned} {[3979 / 6223] /[51 / 56]=0.64 / 0.91=0.70=} & 30 \% \text { signal } \\ & \text { reduction of } \\ & \text { one allele in } \\ & \text { the tumor } \\ & \text { compared } \\ & \text { with the } \\ & \text { normal } \\ & \text { sample }\end{aligned}$

The numbers 6333 and 3979 are the peak heights (ht) of allele 1 and allele 2, respectively, of the tumor sample (Fig. 2b). The numbers 56 and 51 are the peak heights of allele 1 and allele 2, respectively, of the control sample (Fig. 2a). From these tumors, tumor-fields of 200 to 500 cells were microdissected. The DNA derived from the microdissected tumor cells was amplified using the D15S126 amplification primers and an increase of signal reduction of one allele in the tumor sample was found. In one tumor, the second allele was completely lost. Figure 2c shows allelic loss at D15S126 in the microdissected tumor sample. The two other tumor samples displayed $53 \%$ to $55 \%$ of signal reduction of one allele tumor sample when compared with the normal sample after microdissection (results not shown).

In addition, for the D6S265 marker located on chromosome 6, a near-threshold value of allelic loss 
was found in a tumor sample (Fig. 3). Amplification and gene scan analysis of nonmicrodissected tumor cells resulted in two alleles (Fig. 3b). One allele in the tumor sample showed a reduced intensity when compared with the normal sample (Fig. 3a), which was derived from microdissected stromal cells (Fig. 3a). Amplification and gene scan analysis of microdissected normal stromal cells showed two alleles of comparable heights (Fig. 3a). LOH of this sample was calculated as follows:

$\begin{aligned} {[3375 / 5320] /[90 / 108]=0.63 / 0.83=0.76=} & 24 \% \text { signal } \\ & \text { reduction of } \\ & \text { one allele in } \\ & \text { the tumor } \\ & \text { compared } \\ & \text { with the } \\ & \text { normal } \\ & \text { sample }\end{aligned}$

The numbers 5320 and 3375 are the peak heights of allele 1 and allele 2, respectively, of the nonmicrodissected tumor sample (Fig. 3b). The numbers 108 and 90 are the peak heights of allele 1 and allele 2, respectively, of the control sample (Fig.3a).

DNA was isolated from 200 microdissected tumor cells (Fig. 3c) and signal reduction of one allele in the tumor sample, compared with the normal sample, was calculated:

$\begin{aligned} {[168 / 597] /[90 / 108]=0.28 / 0.83=0.34=} & 66 \% \text { signal } \\ & \text { reduction of } \\ & \text { one allele in } \\ & \text { the tumor } \\ & \text { compared } \\ & \text { with the } \\ & \text { normal } \\ & \text { sample }\end{aligned}$

The numbers 597 and 168 are the peak heights of allele 1 and allele 2, respectively, of the microdissected tumor sample (Fig. 3b). The numbers 108 and 90 are the peak heights of allele 1 and allele 2, respectively, of the control sample (Fig. 3a).

\section{High Density Microsatellite Analysis in Primary Tumors and Lymph Node Metastases}

HLA class $I, \beta 2 m$, and TAP expression. A panel of nine paired tumor samples derived from primary $(\mathrm{HN})$ and metastatic lesions $(L)$ of the head and neck, were subjected to high density microsatellite analysis. HLA class I, $\beta 2 \mathrm{~m}$, TAP1, and TAP2 expression in these tumors was established by immunohistochemical procedures using the mAbs W6/32, HCA2, HC10, anti$\beta 2 \mathrm{~m}$, and antibodies raised against TAP1 and TAP2. Table 1 (left panel) shows HLA class I, $\beta 2 \mathrm{~m}$, TAP1, and TAP2 expression in the primary $(\mathrm{HN})$ and metastatic $(\mathrm{L})$ lesions. Six primary HNSCCs (HN37, 38, 41, 54, 20, and 8) showed heterogeneous or negative HLA class I heavy chain expression when analyzed with the locusspecific HCA2 and HC10 mAbs. HN20 showed negative HLA-A expression with retention of HLA-B/C expression. Three of these tumors (HN37, 38, and 41) also displayed down-regulated monomorphic HLA class I surface expression after staining with W6/32 mAbs. Down-regulated monomorphic HLA class I surface expression always coincided with downregulated $\beta 2 \mathrm{~m}$ expression (HN37, 38, and 41 ).

Comparable down-regulated HLA class I and $\beta 2 \mathrm{~m}$ expression was seen in the primary and metastatic lesions of 5 HNSCCs (Cases HN+L37, 38, 41, 54, and 20). Case HN+L8 displayed heterogeneous HLA-A and $\mathrm{HLA}-\mathrm{B} / \mathrm{C}$ expression in the primary tumor, whereas the autologous lymph node metastasis displayed negative HLA-A expression with retention of HLA-B/C expression. TAP1 expression was down-regulated in the primary and metastatic lesions of three cases with downregulated HLA class I expression ( $\mathrm{HN}+\mathrm{L} 37,38$, and 20). None of the tumors displayed down-regulated or lost TAP2 expression. Normal HLA class I, $\beta 2 \mathrm{~m}$, and TAP expression was found in Cases $\mathrm{HN}+\mathrm{L} 43,44$, and 45. These cases were included in our $\mathrm{LOH}$ studies as a control for tumors with normal HLA class I, $\beta 2 \mathrm{~m}$, TAP1, and TAP2 expression.

\section{High Density Microsatellite Analysis in Primary Lesions}

DNA was isolated from the panel of primary and metastatic lesions, which contained at least $60 \%$ tumor cells, and used for high density microsatellite analysis. DNA derived from autologous peripheral blood lymphocytes (PBLs) was used as a control. Twelve markers located in the HLA region (D6S291, TAP1, D6S273, TNFd, MIB, C141, C125, C143, D6S265, D6S510, D6S105, and D6S276), a centromeric marker (D6S473), and a telomeric marker (D6S277) were used. Results obtained by application of these markers are shown in Table 1, right panel.

In addition, a marker located on the $6 \mathrm{q}$ arm, D6S311, was used. Each primary tumor with downregulated HLA expression (HN37, 38, 41, 54, 20, and 8 ) displayed allelic loss at $6 p$, and specifically at $6 \mathrm{p} 21.3$, for at least one marker. Of these tumors, three primary tumors (HN38, 54, and 20) displayed allelic loss at the majority of the informative 6p21.3-located markers ranging from D6S291 to D6S105. One of these tumors (HN38) displayed allelic loss at all informative $6 p$ markers, whereas heterozygosity was retained at the chromosome $6 q$ marker D6S311. Three primary tumors with down-regulated HLA class I expression (HN37, 41, and 8) displayed allelic loss at 1-3 loci, only. Single allelic losses were found at D6S265 (HN37) and at D6S105 (HN8). One tumor with normal HLA class I expression (HN44) displayed allelic losses at $6 \mathrm{p} 21.3$. Allelic loss in this tumor ranged from marker TNFd to C125 (marker C143 was not informative), which comprised the HLA class III-HLA class I junction, including the HLA-B gene. Telomeric $6 p$ loss was found in $\mathrm{HN} 8$ and $\mathrm{HN} 45$. Allelic loss at $6 \mathrm{q}$ was found in 2 of 6 primary tumors (HN41+43).

\section{High Density Microsatellite Analysis in Associated Lymph Node Metastases}

To study the role of chromosomal deletions at $6 p$, and in particular at 6p21.3, in tumor progression, we 
Table 1. Immunohistochemical Staining and Chromosome 6 Loss of Heterozygosity Analysis in Nine Primary Head and Neck Squamous Cell Carcinomas and Lymph Nodes

\begin{tabular}{|c|c|c|c|c|c|c|c|c|c|c|c|c|c|c|c|c|c|c|c|c|c|}
\hline \multirow[b]{2}{*}{ Tumor } & \multicolumn{6}{|c|}{ mAbs } & \multicolumn{15}{|c|}{ Chromosome 6 Markers } \\
\hline & $W 6 / 32$ & $\mathrm{aB} 2 \mathrm{~m}$ & HCA2 & $\mathrm{HC} 10$ & TAP1 & TAP2 & 311 & 473 & 291 & TAP1 & 273 & TNFd & MIB & C141 & $1 \mathrm{C} 125$ & C143 & 265 & 510 & 105 & 276 & 277 \\
\hline HN37 & w & w & - & - & w & + & $\mathrm{N}$ & $\mathrm{N}$ & $\mathrm{N}$ & $\mathrm{N}$ & $\mathrm{N}$ & $\mathrm{N}$ & $\mathrm{N}$ & $\mathrm{N}$ & $\mathrm{N}$ & $\mathrm{N}$ & L & $\mathrm{N}$ & $\mathrm{N}$ & $\mathrm{N}$ & $N$ \\
\hline L37 & w & w & - & $\mathrm{h}$ & $\mathrm{h}$ & + & $\mathrm{N}$ & $\mathrm{N}$ & $\mathrm{N}$ & N & $\mathrm{N}$ & $\mathrm{N}$ & N & N & $\mathrm{N}$ & N & $\mathrm{L}$ & $\mathrm{N}$ & $\mathrm{N}$ & $\mathrm{N}$ & N \\
\hline HN38 & w & w & - & - & $\mathrm{h}$ & + & $\mathrm{N}$ & $\mathrm{H}$ & $\mathrm{L}$ & $\mathrm{L}$ & $\mathrm{L}$ & $\mathrm{L}$ & $\mathrm{L}$ & L & $\mathrm{L}$ & $\mathrm{L}$ & $\mathrm{L}$ & $\mathrm{L}$ & $\mathrm{L}$ & $\mathrm{H}$ & $\mathrm{H}$ \\
\hline L38 & w & w & - & - & w & + & $\mathrm{N}$ & $\mathrm{H}$ & L & L & L & L & L & L & L & L & L & $\mathrm{L}$ & L & $\mathrm{H}$ & $\mathrm{H}$ \\
\hline HN41 & $\mathrm{h}$ & $\mathrm{h}$ & $\mathrm{h}$ & $\mathrm{h}$ & + & + & $\mathrm{L}$ & $\mathrm{N}$ & $\mathrm{L}$ & $\mathrm{N}$ & $\mathrm{N}$ & $\mathrm{N}$ & $\mathrm{N}$ & $\mathrm{N}$ & $\mathrm{N}$ & $\mathrm{H}$ & $\mathrm{N}$ & $\mathrm{N}$ & $\mathrm{L}$ & $\mathrm{H}$ & $\mathrm{H}$ \\
\hline L41 & $\mathrm{h}$ & $\mathrm{h}$ & $\mathrm{h}$ & $\mathrm{h}$ & + & + & $\mathrm{L}$ & $\mathrm{N}$ & L & $\mathrm{N}$ & $\mathrm{N}$ & $\mathrm{N}$ & $\mathrm{N}$ & $\mathrm{N}$ & $\mathrm{N}$ & $\mathrm{H}$ & $\mathrm{N}$ & $\mathrm{N}$ & L & $\mathrm{H}$ & $\mathrm{H}$ \\
\hline HN54 & + & + & $\mathrm{h}$ & $\mathrm{h}$ & + & + & $\mathrm{N}$ & $\mathrm{N}$ & $\mathrm{H}$ & $\mathrm{H}$ & $\mathrm{L}$ & $\mathrm{L}$ & $\mathrm{L}$ & L & $\mathrm{L}$ & $\mathrm{H}$ & $\mathrm{H}$ & $\mathrm{H}$ & $\mathrm{L}$ & $\mathrm{N}$ & $\mathrm{N}$ \\
\hline L54 & + & + & $\mathrm{h}$ & $\mathrm{h}$ & + & + & $\mathrm{N}$ & $\mathrm{N}$ & $\mathrm{H}$ & $\mathrm{H}$ & $\mathrm{L}$ & $\mathrm{L}$ & $\mathrm{L}$ & $\mathrm{L}$ & $\mathrm{L}$ & $\mathrm{H}$ & $\mathrm{H}$ & $\mathrm{H}$ & $\mathrm{L}$ & $\mathrm{N}$ & $\mathrm{N}$ \\
\hline HN2O & + & + & - & + & $\mathrm{h}$ & + & $\mathrm{N}$ & $\mathrm{N}$ & $\mathrm{N}$ & $\mathrm{H}$ & $\mathrm{L}$ & $\mathrm{L}$ & $\mathrm{L}$ & $\mathrm{L}$ & $\mathrm{N}$ & $\mathrm{H}$ & $\mathrm{L}$ & $\mathrm{L}$ & $\mathrm{H}$ & $\mathrm{N}$ & $\mathrm{H}$ \\
\hline L20 & + & + & - & + & $\mathrm{h}$ & + & $\mathrm{N}$ & $\mathrm{N}$ & $\mathrm{N}$ & $\mathrm{H}$ & $\mathrm{L}$ & $\mathrm{L}$ & $\mathrm{L}$ & $\mathrm{L}$ & $\mathrm{L}$ & $\mathrm{H}$ & $\mathrm{L}$ & $\mathrm{L}$ & $\mathrm{H}$ & $\mathrm{N}$ & $\mathrm{H}$ \\
\hline HN8 & + & + & $\mathrm{h}$ & $\mathrm{h}$ & + & + & $\mathrm{N}$ & $\mathrm{N}$ & $\mathrm{N}$ & $\mathrm{N}$ & $\mathrm{H}$ & $\mathrm{N}$ & $\mathrm{N}$ & $\mathrm{N}$ & $\mathrm{N}$ & $\mathrm{H}$ & $\mathrm{N}$ & $\mathrm{N}$ & $\mathrm{L}$ & $\mathrm{N}$ & $\mathrm{L}$ \\
\hline L8 & + & + & - & + & + & + & $\mathrm{N}$ & $\mathrm{N}$ & $\mathrm{N}$ & $\mathrm{N}$ & $\mathrm{H}$ & $\mathrm{L}$ & $\mathrm{N}$ & $\mathrm{N}$ & $\mathrm{N}$ & $\mathrm{H}$ & $\mathrm{N}$ & $\mathrm{N}$ & L & $N$ & $\mathrm{~L}$ \\
\hline HN43 & + & + & + & + & + & + & $\mathrm{L}$ & $\mathrm{N}$ & $\mathrm{N}$ & $N$ & $\mathrm{~N}$ & $\mathrm{~N}$ & $\mathrm{~N}$ & $\mathrm{~N}$ & $\mathrm{~N}$ & $\mathrm{H}$ & $\mathrm{N}$ & $\mathrm{N}$ & $\mathrm{N}$ & $\mathrm{N}$ & $\mathrm{N}$ \\
\hline L43 & + & + & + & + & + & + & $\mathrm{N}$ & $\mathrm{N}$ & $N$ & $\mathrm{~L}$ & $\mathrm{~N}$ & $N$ & $\mathrm{~N}$ & $\mathrm{~N}$ & $\mathrm{~N}$ & $\mathrm{H}$ & $\mathrm{N}$ & $\mathrm{N}$ & $\mathrm{N}$ & $N$ & $N$ \\
\hline HN44 & + & + & + & + & + & + & $\mathrm{N}$ & $\mathrm{N}$ & $\mathrm{H}$ & $\mathrm{N}$ & $\mathrm{N}$ & $\mathrm{L}$ & $\mathrm{L}$ & $\mathrm{H}$ & $\mathrm{L}$ & $\mathrm{H}$ & $\mathrm{N}$ & $N$ & $\mathrm{~N}$ & $\mathrm{~N}$ & $N$ \\
\hline L44 & + & + & + & + & + & + & $\mathrm{N}$ & $\mathrm{N}$ & $\mathrm{H}$ & $\mathrm{N}$ & $\mathrm{N}$ & $\mathrm{N}$ & $\mathrm{N}$ & $\mathrm{H}$ & $\mathrm{N}$ & $\mathrm{H}$ & $\mathrm{N}$ & $\mathrm{N}$ & $\mathrm{N}$ & $\mathrm{N}$ & $N$ \\
\hline HN45 & + & + & + & + & + & + & $N$ & $\mathrm{~N}$ & $N$ & $H$ & $\mathrm{H}$ & $\mathrm{N}$ & $\mathrm{N}$ & $\mathrm{N}$ & $\mathrm{N}$ & $\mathrm{H}$ & $\mathrm{N}$ & $\mathrm{N}$ & $\mathrm{N}$ & $N$ & L \\
\hline L45 & + & + & + & + & + & + & $\mathrm{N}$ & $\mathrm{N}$ & $\mathrm{N}$ & $\mathrm{H}$ & $\mathrm{H}$ & $\mathrm{N}$ & $\mathrm{N}$ & $\mathrm{N}$ & $\mathrm{N}$ & $\mathrm{H}$ & $\mathrm{N}$ & $\mathrm{N}$ & $\mathrm{N}$ & $\mathrm{N}$ & $\mathrm{L}$ \\
\hline
\end{tabular}

Patterns of immunohistochemical staining of HLA Class I (W6/32), $\beta 2 \mathrm{~m}$ (anti- $\beta 2 \mathrm{~m}$ ), HLA-A (HCA2), HLA-B/C (HC10), and TAP 1 (AK1.7) and TAP 2 (T2-429.3) (left panel) and loss of heterozygosity (LOH) on chromosome 6 (right panel) of 9 head and neck squamous cell carcinomas (HNSCCs) (HN) and lymph nodes (L). Left panel: n, normal, w, weak, h, heterogeneous, -, negative staining. Right panel: N, no LOH, L, LOH, H, homozygous.

$\square=$ normal expression (left panel) or no LOH (right panel).

$=$ down-regulated expression (left panel) or LOH (right panel).

$=$ not informative (homozygous, $\mathrm{H}$ ).

applied the autologous lymph node metastases to high density microsatellite analysis. Table 1 includes the results obtained by high density microsatellite analysis of the lymph node metastases (L). In accordance with the HLA class I expression patterns, identical LOH patterns were found in four primary and autologous lymph node metastases with downregulated HLA class I expression ( $\mathrm{HN}+\mathrm{L} 37, \mathrm{HN}+\mathrm{L} 38$, $\mathrm{HN}+\mathrm{L} 41$, and $\mathrm{HN}+\mathrm{L} 54)$. Case $20(\mathrm{HN}+\mathrm{L} 20)$ displayed a different pattern in the primary and the metastatic lesion. The primary tumor contained two noncontinuous regions of loss: one region between D6S273 and C141, and the second region between D6S265 and D6S510. Heterozygosity at C125, which is located at the HLA-B/C region, was retained in the primary tumor. Marker C143 was not informative. The lymph node metastasis contained one region of allelic loss ranging from D6S273 to D6S510. In Case 8 (HN+L8), the metastatic lesion displayed in addition to loss at the 6p21.3-located marker D6S105, allelic loss at marker TNFd. Allelic loss at this marker was not found in the primary tumor.

Two (2 of 3) cases with normal HLA class I expression $(\mathrm{HN}+\mathrm{L} 43$ and $\mathrm{HN}+\mathrm{L} 44)$ showed differential allelic loss patterns at $6 \mathrm{p} 21.3$ in the primary versus the metastatic lesion. Case $43(\mathrm{HN}+\mathrm{L} 43)$ showed allelic loss at marker TAP1 in the metastatic lesion. Allelic loss at this marker was not found in the primary tumor. Case $44(\mathrm{HN}+\mathrm{L} 44)$ displayed allelic losses between marker TNFd and $\mathrm{C} 125$ in the primary tumor, which was not found in the metastatic lesion. The third case with normal HLA class I expression, Case 45 $(\mathrm{HN}+\mathrm{L} 45)$ contained single allelic loss at D6S277 (located at the $6 p$ telomere), both in the primary and the metastatic lesion.

\section{Discussion}

Down-regulation of HLA class I expression has been reported in various tumors and this singularity may 
provide tumor cells with a mechanism to escape immune recognition by cytotoxic T cells. Loss of HLA class I expression in tumors has mainly been established by immunohistochemical procedures using monoclonal antibodies (mAbs) directed against monomorphic, locus-, and allele-specific determinants of HLA class I molecules (Garrido et al, 1997). Due to the cross-reactivity of several locus-specific mAbs and the scarcity of allelespecific mAbs, the exact frequency and nature of altered HLA class I expression are still unclear. Moreover, immunohistochemical procedures are limited in revealing the underlying mechanisms responsible for downregulated HLA class I expression. Interpretation of HLA class loss phenotypes in tumors is even more complicated by the heterogeneity of tumors. The development of reliable and robust molecular techniques is required to study HLA class I loss in tumors. One important innovation in these studies is microdissection, which enables isolation of tumor cells without co-isolation of normal cells that could mask alterations in tumor cells. In addition, this technique offers the possibility to study heterogeneity in tumors.

Various underlying mechanisms can result in loss of HLA class I expression in tumors (Ferrone and Marincola, 1995). One of these mechanisms, LOH of chromosome $6 \mathrm{p}$, has been reported in various tumors of different origin (Foulkes et al, 1993; 1999a; Randerson et al, 1996). Previously, we studied chromosomal deletions of the HLA region at 6 p21.3 in head and neck squamous cell carcinomas using a limited panel of microsatellite markers (Feenstra et al, 1999b). LOH was studied using DNA isolated from ten $10 \mu \mathrm{m}$ cryostat sections containing at least $60 \%$ of tumor cells. To demonstrate $\mathrm{LOH}$, paired samples of tumor and normal DNA were analyzed. Normal DNA was used as a control because the efficiency of amplification varies between alleles and between samples. The ratio between two alleles in a heterozygous sample should remain constant. By comparing tumor and normal DNA, a change in the ratio indicates allelic loss. Most samples showed residual amplification of the lost allele in the tumor from co-isolated DNA derived from stromal and infiltrating cells. Allelic loss was assigned if $25 \%$ and more of signal reduction of one allele was shown in the tumor sample compared with the normal sample. The majority of samples with allelic loss, showed $50 \%$ and more relative signal reduction. In four tumors, near-threshold values of signal reduction were found. To clarify whether these samples displayed allelic loss, tumor cells from these samples were microdissected to avoid co-isolation of stromal and infiltrating cells. In addition, normal stromal and epithelial cells of these tumors were microdissected and used as a control. Microdissection of tumor resulted in clear allelic loss in these tumors. Signal reduction in the microdissected tumor cells, when compared with normal tissue, increased from nearthreshold values (approximately 25\%) to 53\% to $100 \%$. The initial low signal reduction in the nonmicrodissected tumor tissue, may have resulted from the heterogeneity of these tumors. Figure 2 shows that the tumors display heterogeneous $\beta 2 \mathrm{~m}$ (Fig. $2 \mathrm{~b}$ ) and HLA class I (Fig. 3b) expression. Due to this heterogeneity, only a low percentage of the tumor cells may contain allelic loss. Alternatively, the initial low signal reduction in the nonmicrodissected tumor tissue may result from the high percentage of infiltrating cells. The presence of a high percentage of infiltrating cells in tissue impedes estimation of the percentage of tumor cells. Our results on microdissected tumor cells show that assigning $\mathrm{LOH}$ at $25 \%$ signal reduction in the tumor compared with the normal sample is accurate. In addition, we show that microdissection is an important technique to identify $\mathrm{LOH}$ in heterogeneous tumor samples or tumor samples that contain a low percentage of tumor cells.

Next, we analyzed LOH in nine paired primary and metastatic lesion of the head and neck by high density microsatellite analysis. Allelic loss at chromosome $6 p$ was previously studied by seven STR markers (D6S473, D6S291, D6S273, D6S265, D6S105, D6S276, and D6S277) covering the chromosome $6 p$ from centromere to telomere and correlated with HLA class I and TAP1 expression. Allelic loss was found with high frequencies and significantly correlated with down-regulated HLA class I and TAP1 expression (Fisher's exact test $p=0.0196$ and $p=0.0464$, respectively) (Feenstra et al, 1999b). However given the genomic distances between marker and HLA genes, allelic loss at a microsatellite marker may not necessarily reflect loss of HLA genes. High density microsatellite analysis was developed to increase the probability that allelic loss at a microsatellite marker coincides with loss of expression of HLA genes. The extended panel of microsatellite markers (TAP1, TNFd, MIB, C141, C125, C143, and D6S510) was selected for the close proximity to the HLA and TAP genes (see Fig. 1 and Table 2). Therefore, in total, 14 STRs were used to study $\mathrm{LOH}$ at chromosome $6 \mathrm{p}$, and allelic loss was correlated with HLA class I expression. In addition, one marker (D6S311) located at chromosome $6 q$ was used to identify loss of the $6 q$ arm. Loss at $6 p$ and $6 q$ indicates loss of the entire chromosome 6. Three tumors $(\mathrm{HN}+\mathrm{L} 38,54$, and 20) displayed allelic losses at the majority of the markers. This result indicates that the coding regions of the HLA genes are lost as well in these tumors. Indeed, LOH in these tumors correlated with down-regulated HLA class I expression. Case 20 displayed two regions of allelic loss with retention of heterozygosity at marker C125. Our hypothesis is that the noncontinuous deletions occurred at separate chromosomes. It is not possible to distinguish between losses on separate chromosomes by application of microsatellites.

Case 38 showed $\mathrm{LOH}$ at all $6 \mathrm{p}$ markers indicating loss of the entire $6 \mathrm{p}$ arm. To study loss of the entire chromosome 6, the 6q located marker D6S311 was applied. No allelic loss at this marker was identified, indicating that the $6 \mathrm{q}$ arm was still present. Loss of an entire chromosome is believed to result from nondisjunction. Nondisjunction is not the most common mechanism by which LOH on chromosome 6 occurs. Deletions and recombinations seem to be the most important mechanism contributing to $\mathrm{LOH}$ on $6 \mathrm{p}$ 


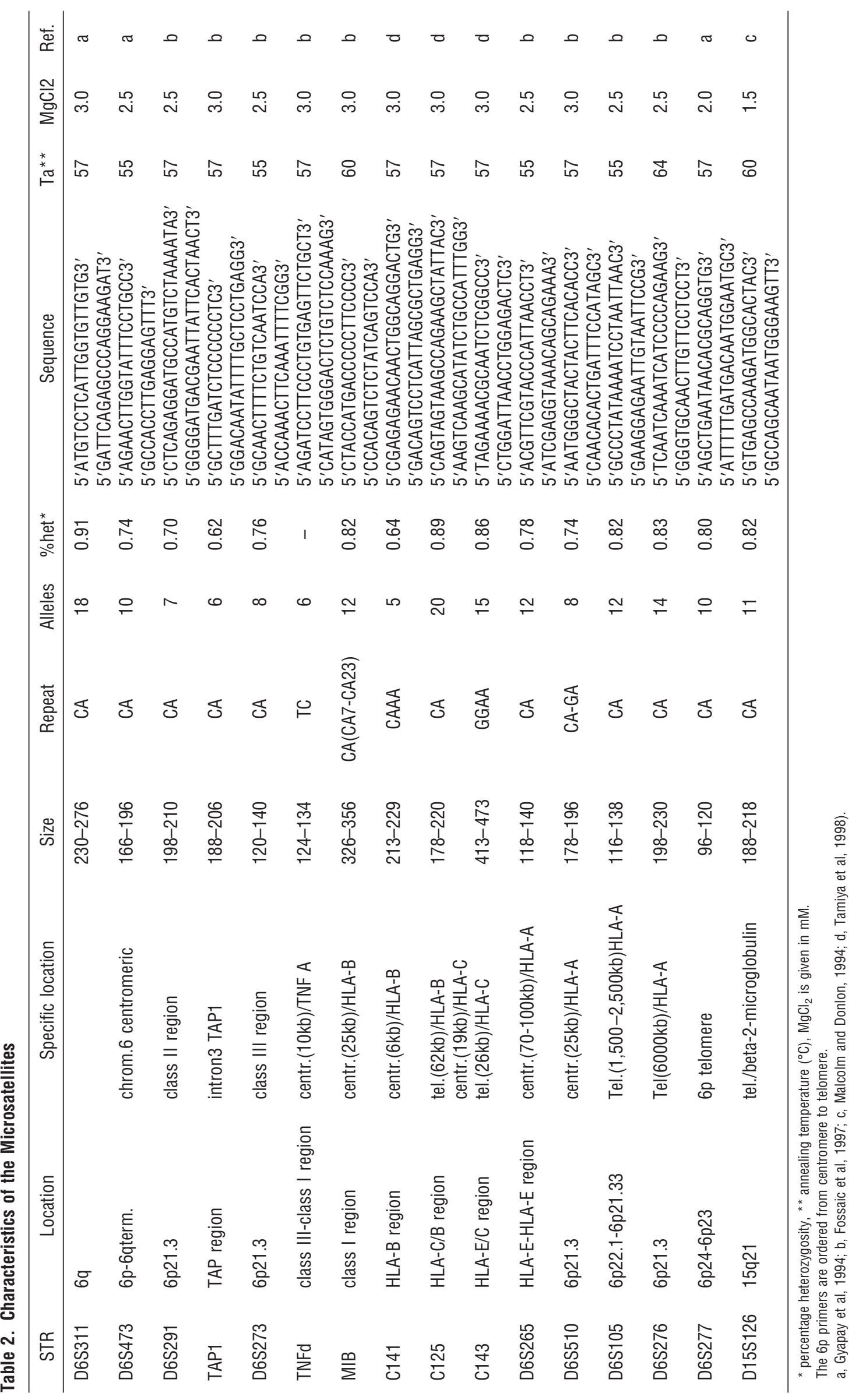


(Feenstra et al, 1999b; Foulkes et al, 1993). In two (2 of 3 ) cases with normal HLA class I expression, allelic loss at 6 p21.3 was identified with high density microsatellite analysis that was not identified by application of the 7 STRs used in our previous study.

One primary tumor with normal HLA class I expression (HN44) showed a deletion ranging from TNFd to C125, which includes the HLA-B gene. Genomic loss in this tumor did not result in down-regulated HLA-B expression as was analyzed by immunohistochemical procedures using HLA-B/C locus specific mAbs. Because not all HLA-B/C alleles are recognized by $\mathrm{HC10}$, it is possible that the lost HLA-B allele was not recognized by $\mathrm{HC} 10$ in the first place. In this case, genomic loss of this allele will remain undetected by immunostaining with the HC10 mAbs. Application of allele-specific mAbs on HLA-typed samples will be required to further investigate this sample.

We were specifically interested in allelic loss at the TAP1 marker. Marker D6S291 appeared to be an informative marker, and allelic loss at this marker correlated significantly with down-regulated TAP1 expression ( $p=0.0464$ ) (Feenstra et al, 1999b). However, the genomic distance between D6S291 and TAP is approximately $5 \mathrm{Mb}$ (Tripodis et al, 1998). To study genomic loss of the TAP gene, we applied the TAP1 marker, which is located in intron 3 of the TAP1 gene (Carrington and Mann, 1994). LOH at the TAP1 marker was compared with down-regulated TAP1 expression. In one case (HN+L38) down-regulated TAP1 expression indeed correlated with loss at the TAP1 marker. In Case 41 ( $\mathrm{HN}+\mathrm{L} 41)$, allelic loss was identified at marker D6S291, whereas TAP1 expression was normal. Application of the TAP1 marker revealed no allelic loss of TAP1.

To study the role of LOH in tumor progression, high density microsatellite analysis was applied to primary and metastatic lesions of the head and neck. In 5 of 9 cases (HN+L37, 41, 54, 20, and 45) the same LOH pattern was found in the primary tumor as in the lymph node metastases. This indicates that in these patients $\mathrm{LOH}$ occurred before the tumor became metastatic. In Cases 8 and 44 (HN+L8 and 44) allelic loss was found in the primary tumor but not in the lymph node metastases. In contrast, Case $43(\mathrm{HN}+\mathrm{L} 43)$ displayed an allelic loss in the lymph node metastasis, which was not found in the primary tumor. The latter cases may be explained by the biological heterogeneity of the primary tumor. LOH may have occurred in only a small number of tumor cells of the primary HNSCC, which appeared to be below threshold detection but were able to metastasise to the lymph node. Microdissection of multiple areas from these samples will be required to prove this assumption.

This study shows that HNSCC with down-regulated HLA class I expression frequently show allelic loss at 6p21.3. High density mapping using an extended panel of 12 6p21.3-located microsatellite markers identified additional allelic losses that were not identified in our previous study using only five 6p21.3located markers. Moreover, loss of HLA class I expression was not identified by immunohistochemical procedures, using monomorphic and locus specific mAbs, in some of these tumors. $\mathrm{LOH}$ analysis by amplification of microsatellite markers and subsequent fluorescent detection is a rapid and sensitive technique to predict HLA class I loss phenotypes in tumors. In our previous and current study, LOH was assigned at $25 \%$ or more signal reduction of one allele in the tumor when compared with the normal sample. Assigning loss at $25 \%$ was validated by microdissection. Microdissection of tumor cells facilitates identification of loss in heterogeneous tumor samples or tumor samples containing low percentages of tumor cells. Appropriate HLA-LOH analysis requires carefully selected markers covering the $6 \mathrm{p} 21.3$ region. Important criteria for these markers are the number of alleles, percentage of heterozygosity and the location relative to HLA and TAP genes. Previously we proposed a panel of 5 microsatellite markers covering the whole 6p21.3 region, ie D6S291, D6S273, D6S265, D6S105, and D6S276 (Ramal et al, 1999). The present study shows that in addition to these markers, application of markers in close proximity to HLA class I and TAP genes is required to accurately locate HLA loss in tumors. Markers TAP1, C125, and D6S510 are, with regard to percentage of heterozygosity and location to HLA genes, the most suitable markers to include. To perform high density microsatellite analysis using multiple STRs on tumor samples, the development of multiplex assays will be of great importance.

\section{Materials and Methods}

\section{Patients and Tumor Specimens}

HNSCCs used in this study were derived from a panel of 55 HNSCC that was previously studied for HLA class I and $\beta 2 \mathrm{~m}$ expression by immunohistochemical procedures and for allelic loss at $6 p$ (including the HLA region at $6 \mathrm{p} 21.3$ ) and $15 \mathrm{q}$ (flanking the $\beta 2 \mathrm{~m}$ gene) (Feenstra et al, 1999a). Four primary lesions showing a near-threshold value of signal reduction for $\mathrm{LOH}$ were selected for microdissection. Nine primary and metastatic lesions used for high density microsatellite analysis were also selected from this panel. Tissue was obtained from patients undergoing tumor resection at the University Medical Center, Utrecht, The Netherlands. All tissues were snap frozen in liquid nitrogen and stored at $-80^{\circ} \mathrm{C}$. Histopathological diagnosis and grading were confirmed on hematoxylin and eosin stained frozen sections according to the classification in "Histological typing of Tumors of the Upper Respiratory Tract and Ear" (Shanmugaratnam and Sobin, 1991). The samples were derived from the oral cavity or the larynx, and the majority of samples were moderately differentiated.

\section{Antibodies}

The following primary MoAbs were used: W6/32 against HLA class I heavy chain/ $\beta 2 \mathrm{~m}$ complex (DAKO A/S, Glostrup, Denmark), anti- $\beta 2 \mathrm{~m}$ against $\beta 2 \mathrm{~m}$ (Immunotech, Margency, France), and HCA2 and HC10 defining HLA-A heavy chain and HLA-B/C heavy 
chain, respectively, kindly provided by Dr. H. L. Ploegh (MIT, Boston, Massachusetts) (Stam et al, 1990). The AK1.7 and the T2-429.3 antibodies against TAP1 and TAP2, respectively, were a kind gift from Dr. M. J. Kleijmeer (UCMU, The Netherlands) (Kleijmeer et al 1992). The primary antibodies used in this study, their specificity and origin are summarized in Table 3.

\section{Immunohistochemical Procedures}

Immunohistochemical staining was performed as described previously (Feenstra et al, 1999a). Cryostat sections (8 $\mu \mathrm{m}$ thick) were immunostained for HLA-class I, $\beta 2 \mathrm{~m}$, and TAP. W6/32, anti- $\beta 2 \mathrm{~m}, \mathrm{AK} 1.7$, and T2-429.3 were detected by the streptavidin-biotin technique. Horse anti-mouse biotin-conjugated immunoglobulin was obtained from Vector Laboratories (Burlingame, California), and the streptavidin-peroxidase conjugate was obtained from Immunotech (Margency, France). For the detection of HCA2 and HC10 mAbs, the sections were incubated with second step rabbit anti-mouse peroxidase conjugate (RAMPO) and third-step antibody swine anti-rabbit peroxidase conjugate (SWARPO). Both antibodies were purchased from DAKO AVS (Glostrup, Denmark).

Visualization of the peroxidase label was performed with DAB (3.3'-diaminobenzidine tetra-hydrochloride), purchased from Sigma (St. Louis, Missouri). The sections were counterstained with Mayer's hematoxylin. Slides were analyzed in three independent scores. The staining intensity of the tumor cells was scored as normal (staining of the tumor cells showed the same intensity as the surrounding stromal cells), weak (staining of the tumor cells was significantly less when compared with staining of the surrounding stromal cells), negative (no staining of the tumor cells), and heterogenous (normal and weak, normal and negative, or weak and negative staining of the tumor cells from one section) (Feenstra et al, 1999b). Necrotic or keratinized tumor areas were not taken into consideration. Isotype controls were applied for every tumor used in this study.

\section{Laser-Assisted Single-Cell Microdissection}

Frozen sections (12 $\mu \mathrm{m}$ thick) were mounted on PEN-foil (1, $35 \mu \mathrm{m}$ thin polyethylene foil, PALM GmbH, Wolfratshausen, Germany); this serves as a supporting backbone of the catapulted specimen. The sections were air

Table 3. Primary Antibodies

\begin{tabular}{llcc}
\hline Antibody & \multicolumn{1}{c}{ Specificity } & Dilution Used & Ref \\
\hline W6/32 & $\beta 2 \mathrm{~m}+$ heavy chain & $1: 100$ & $\mathrm{a}$ \\
anti- $\beta 2 \mathrm{~m}$ & $\beta 2 \mathrm{~m}$ & $1: 100$ & $\mathrm{~b}$ \\
HCA2 & HLA-A & $1: 40$ & $\mathrm{C}$ \\
HC10 & HLA-B/C & $1: 50$ & $\mathrm{C}$ \\
AK1.7 & TAP1 & $1: 50$ & $\mathrm{~d}$ \\
T2-429.3 & TAP2 & $1: 200$ & $\mathrm{~d}$ \\
\hline
\end{tabular}

a, Dako, Glostrup, Denmark; b, Immunotech, Margency, France; c, Stam et al, 1990; d, Kleijmeer et al, 1992. dried and stained with a $0.1 \%$ solution of toluidin blue in $0.1 \times$ phosphate buffered saline (PBS) for 30 seconds. Groups of tumor cells (200-500 cells) were dissected by laser assisted microdissection using Robot-Microbeam (PALM GmbH) equipment. In addition, stromal and epithelial cells (200-500 cells) were dissected and used as control material. The Robot-Microbeam consists of a pulsed nitrogen laser (wavelength, $337 \mathrm{~nm}$ ) coupled through a special interface to a microscope (Leica DM IRD microscope, Leica B.V., Rijswijk, The Netherlands) and equiped with a motorized, computer controlled microscope stage and micromanipulator. The stained section was visualized under the microscope. Simultaneously, activation of the laser beam and a highly precise computer controlled movement of the microscope stage allowed for accurate separation of cells. Unwanted cells can be selectively eliminated with a few laser shots. By increasing the laser energy level on a small area, the selected cells are catapulted into the microfuge cap coated with $1 \mu \mathrm{l}$ of paraffin oil. The increased laser energy did not damage the selected cells. The microfuge cap was held and centered above the line of laser fire with the motorized micromanipulator.

\section{DNA Isolation from Microdissected Cells}

Cells were lysed in $100 \mu \mathrm{l} 1 \times$ PCR II buffer (Perkin Elmer, Foster City, California) containing $400 \mu \mathrm{g}$ Proteinase K (Boehringer Mannheim, Germany), $2.5 \mathrm{~mm} \mathrm{MgCl}$, and 2\% Tween 20 (Riedel-deHaën, Seelze, Germany). The cells were incubated upside-down (the cells were in the cap) for 1 hour at $55^{\circ} \mathrm{C}$ followed by 5 minutes $95^{\circ} \mathrm{C}$ to stop the reaction. From the lysate $5 \mu \mathrm{l}$ was used for polymerase chain reaction (PCR), allowing 20 PCR reactions per lysate. The mixture was kept at $-20^{\circ} \mathrm{C}$.

\section{DNA Extraction from Nonmicrodissected Cells}

From the solid tumor, 12 serially cryostat-sectioned, $10 \mu \mathrm{m}$ slices were collected. The first and last sections were stained with hematoxylin and eosin, and the percentage of tumor tissue was calculated. Only tissues with more than $60 \%$ of tumor cells (as estimated) were used. DNA was isolated using a Qiagen DNA isolation kit (Qiamp Tissue Kit, Westburg, Leusden, The Netherlands). DNA from peripheral blood lymphocytes (PBL) was isolated according to the salting-out method (Miller et al, 1988).

\section{PCR}

For the amplification of microsatellite markers on chromosome 6 , the $5^{\prime}$ site of one of the primers of each primer set was tagged with a blue fluorescent label FAM (Eurogentec, Seraing, Belgium). Details of the selected primers are given in Table 2. The locations of the microsatellite markers on chromosome $6 p$ are given in Figure 1.

TAP1, TNFd, MIB, C141, C125, C143, and D6S510 are the seven additional primers used for high density mapping. D6S311 was used to investigate $6 \mathrm{q}$ loss. PCR was performed in $50 \mu$ l reactions containing $1 \times$ PCR II buffer (Perkin Elmer), 100 ng DNA, 12 pmol of 
each primer combination, $0.8 \mu \mathrm{M}$ dNTPs, $0.4 \mu \mathrm{l}$ Amplitaq DNA polymerase $(5 \mathrm{U} / \mu \mathrm{l})$ (Perkin Elmer), and 1.5-3 mM MgCl2. Amplification was performed in 30 cycles in a PE 480 thermal cycler (Perkin Elmer) as follows: $94^{\circ} \mathrm{C}$ (30 seconds), $55^{\circ} \mathrm{C}$ to $64^{\circ} \mathrm{C}$ (30 seconds), $72^{\circ} \mathrm{C}$ (45 seconds). $\mathrm{MgCl}_{2}$ concentration and annealing temperature was optimized for each primer set (Table 2). Amplification was preceded by a denaturating step $\left(94^{\circ} \mathrm{C}, 4\right.$ minutes) and completed with an extension step $\left(72^{\circ} \mathrm{C}, 5\right.$ minutes).

\section{Microsatellite Analysis}

Microsatellite alleles were size fractionated in a $6 \%$ denaturating polyacrylamide gel in the presence of a 2500-ROX size standard (Applied Biosystems, Foster City, California) on a 373A DNA sequencer running Genescan Analysis 2.0 software (Applied Biosystems). Microsatellite allele sizes and $\mathrm{LOH}$ were determined by using Genotyper software (Applied Biosystems).

$\mathrm{LOH}$ was calculated as follows:

$$
\text { Height of tumor allele } 2 \text { Height of normal allele } 2
$$$$
\text { Height of tumor allele } 1 \text { Height of normal allele } 1
$$

Loss of heterozygosity was assigned if more than $25 \%$ of signal reduction of one allele was shown in the tumor sample when compared with the control PBL sample.

\section{Acknowledgements}

We are grateful to the "Maurits en Anna de Kock Stichting" for their financial support for the micromanipulator; Dr. H. Dullens for developing the application of microdissection; Dr. H. L. Ploegh and Dr. M. J. Kleijmeer for gifts of mAbs. We thank Mr. Dick van Wichen for the processing and the layout of the figures. Ms. Josine van der Mudde is thanked for technical assistance.

\section{References}

Campbell RD and Trowsdale J (1993). Map of the human major histocompatibility complex. Immunol Today 14:349-352.

Carrington M and Mann D (1994). A polymorphic dinucleotide repeat in the third intron of TAP1. Hum Mol Genet 3:218.

Feenstra M, Duran K, Stuy I, van den Tweel J, Slootweg P, de Weger R, Tilanus M. (1999a). Mutations in the $\beta 2 \mathrm{~m}$ gene is not a frequent event in head and neck squamous cell carcinomas with down-regulated HLA class I expression. Human Immunol 60:697-706.

Feenstra M, Veltkamp M, van Kuik J, Wiertsema S, Slootweg P, van den Tweel J, de Weger R, and Tilanus M (1999b). HLA class I expression and chromosomal deletions at $6 p$ and $15 q$ in head and neck squamous cell carcinomas. Tissue Antigens 54:235-245.

Ferrone S and Marincola FM (1995). Loss of HLA class I antigens by melanoma cells: Molecular mechanisms, functional significance and clinical relevance. Immunol Today 16:487-494.

Foulkes WD, Ragoussis J, Stamp GWH, Allan GJ, and Trowsdale J (1993). Frequent loss of heterozygosity on chromosome 6 in human ovarian carcinoma. Br J Cancer 67:551-559.
Fossaic A, Crounau-Roy B, Fauré S, Thomsen M, and CambonThomsen A (1997). Microsatellites in the HLA region: An overview. Tissue Antigens 49:197-214.

Fossaic A, Crounau-Roy B, Fauré S, Thomsen $M$, and Cambon Thomsen A (1998). An update on microsatellites in the HLA region. Tissue Antigens 52:318-352.

Garrido F, Cabrera T, Lopez-Nevot MA, and Ruiz-Cabello F (1995). HLA Class I antigens in human tumors. Adv Cancer Res 67:155-193.

Garrido F, Ruiz-Cabello F, Cabrera T, Perez-Villar JJ, LopezBotet M, Duggan-Keen M, and Stern P (1997). Implications for immunosurveillance of altered HLA class I phenotypes in human tumors. Immunol Today 18:89-95.

Gyapay G, Morissette J, Vignal A, Dib C, Fizames C, Millasseau P, Marc S, Bernardi G, Lathrop M, and Weissenbach J (1994). The 1993-94 Généthon human genetic linkage map. Nat Genet 7:246-249.

Kleijmeer MJ, Kelly A, Geuze HJ, Slot JW, Townsend A, and Trowsdale J (1992). Location of MHC-encoded transporters in the endoplasmatic reticulum and cis-Golgi. Nature 357:342344.

Maffei A, Papadopoulos K, and Harris PE (1997). MHC class I antigen processing pathways. Human Immunol 54:91-103.

Malcolm S and Donlon TA (1994). Report of the second international workshop on human chromosome 15 mapping 1994. Cytogenet Cell Genet 67:2-22.

Miller SA, Dykes DD, and Polesky HFA (1988). A simple salting out procedure for extracting DNA from human nucleated cells. Nucl Acids Res 16:1215.

Ramal LM, Feenstra M, van der Zwan AW, Collado A, Lopez-Nevot MA, Tilanus M, and Garrido F (In Press, 2000). Criteria to define HLA haplotype loss in human solid tumors. Tissue Antigens.

Randerson J, Cawkell L, Jack A, Lewis F, Johnson P, Evans $P$, Barrans S, and Morgan GJ (1996). Fluorescent polymerase chain reaction of a CA repeats on chromosome 6 in the indolent phase of follicular centre cell lymphoma. $\mathrm{Br} \mathrm{J}$ Cancer 74:942-946.

Shanmugaratnam K and Sobin LH (1991). Histological typing of tumors of the upper respiratory tract and ear, second edition. NewYork: Springer-Verlag.

Stam NJ, Vroom ThM, Peters PJ, Pastoors EB, and Ploegh HL (1990). HLA-A and HLA-B specific monoclonal antibodies reactive with free heavy chains in western blot, in paraffinembedded tissue sections and in cryo-immunoelectronmicroscopy. Int Immunol 2:113-125.

Tamiya G, Ota M, Katsuyama Y, Shiina T, Oka A, Makino S, Kimura M, and Inoko H (1998). Twenty-six new polymorphic microsatellite markers around the HLA-B, $-C$ and $-E$ loci in the human class I region. Tissue Antigens 51:337-346.

Townsend $\mathrm{A}$ and Bodmer $\mathrm{H}$. Antigen recognition by class I restricted T lymphocytes (1989). Ann Rev Immunol 7:601-605.

Tripodis N, Mason R, Humphray S, Davies AF, Herberg JA, Trowsdale J, Nizetic D, Senger G, and Ragoussis J (1998). Physical map of human $6 \mathrm{p} 21.2-6 \mathrm{p} 21.3$ : Region flanking the centromeric end of the major histocompatibility complex. Genome Res 8:631-643. 